\section{BIOCONVERSION OF MONENSIN BY A SOIL BACTERIUM, SEBEKIA BENIHANA}

\author{
F. Vaufrey, A. M. Delort, \\ G. JEMINET and G. DAuPhiN*
}

Laboratoire de Chimie Organique Biologique, U.R.A. 485 du C.N.R.S.,

Université Blaise Pascal, Clermont-Ferrand, 63177 Aubiere Cedex - France

(Received for publication February 26, 1990)

Monensin (1), a carboxylic polyether antibiotic has been extensively used as an anticoccidial agent for poultry ${ }^{1)}$ and to improve the efficiency of feed utilization in ruminant animals ${ }^{27}$. Despite the considerable economic and environmental implications of this extensive use in animals, few data are available on the detoxification processes of such molecules. We described recently the bioconversion of nigericin ${ }^{37}$ by Sebekia benihana NRRL 111114). This soil bacterium was found to convert nigericin in three successive steps, giving compounds which had no ionophoric and antibiotic properties.

$S$. benihana also proved to be efficient on monensin, which was converted to three major compounds in similar fashion. This paper deals with the determination of the structures of these three products, and of their antibiotic activity and ionophoric properties.

Monensin ( $40 \mathrm{mg}$ in $2 \mathrm{ml}$ ethanol solution) was bioconverted by whole cells of $S$. benihana NRRL 11111 grown in $100 \mathrm{ml}$ TYG medium as previously described for nigericin ${ }^{3)}$, quantitatively into $M_{1}$ after 24 hours; $M_{1}$ was then oxidized to $M_{2}$ and $\mathrm{M}_{3}$ after 120 hours (Fig. 1). The bioconversion products were detected and isolated as previously described ${ }^{33}$; their $\mathrm{Rf}$ values were as follow; monensin $0.84, M_{1} 0.56, M_{2} 0.26, M_{3} 0.20$. (TLC: $\left.\mathrm{CHCl}_{3}-\mathrm{MeOH}, 9: 1\right)$.

The structures of $M_{1}, M_{2}$ and $M_{3}$ were identified by IR, FAB-MS and NMR spectroscopy ${ }^{3)}$. Monensin, $\mathbf{M}_{1}, \mathbf{M}_{2}$ and $\mathrm{M}_{3}$ have similar IR spectra indicating that the main skeleton of monensin is maintained. FAB $(+)$ experiments confirmed the MW's of monensin derivatives as acid form $\left.(\mathrm{M}+\mathrm{H})^{+}: \mathrm{M}_{1}, 673.5 ; \mathrm{M}_{2}, 689.6 ; \mathrm{M}_{3}, 689.5\right)$. FAB (-) experiments confirmed the MW's of $M_{1}$ and $\left.\mathrm{M}_{2}(\mathrm{M}-\mathrm{H})^{-}: \mathrm{M}_{1}, 671.3 ; \mathrm{M}_{2}, 687.3\right)$. In conclusion, FAB-MS clearly shows the presence of an open terminal ring for $\mathrm{M}_{1}, \mathrm{M}_{2}$ and $\mathrm{M}_{3}$ and an additional

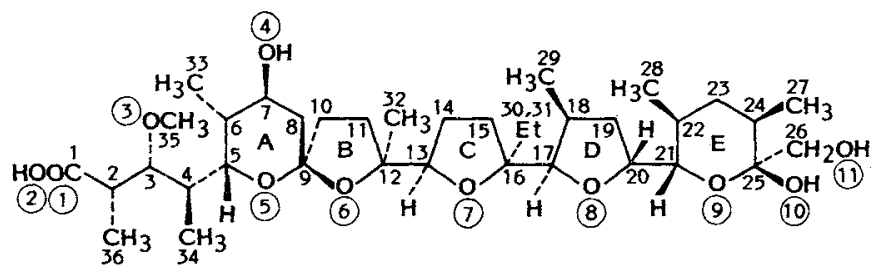

Monensin (1)

Fig. 1. Bioconversion of monensin by Sebekia benihana.

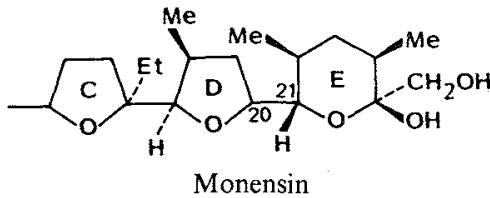

Monensin
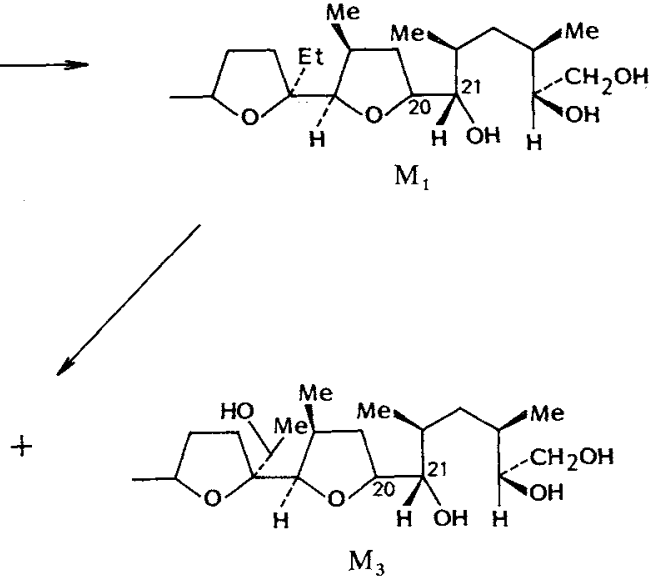
oxidation for $M_{2}$ and $M_{3}$. The structures proposed for $M_{1}, M_{2}$ and $M_{3}$ were finally elucidated by NMR analysis. The general strategy followed for this purpose has been described previously ${ }^{5} \cdot{ }^{13} \mathrm{C}$ and ${ }^{1} \mathrm{H}$ chemical shifts of $\mathrm{M}_{1}, \mathrm{M}_{2}$ and $\mathrm{M}_{3}$ were compared with those of monensin. The main significant differences are reported in Tables 1 and 2. Omitted signals were very similar and in agreement with those described earlier for monensin (acid form) ${ }^{6 \sim 8)}$ suggesting that most of the monensin skeleton is unchanged, especially the carboxyl terminus of the molecule including the $A$ and $B$ rings. The NMR changes observed for $M_{1}$ and $\mathrm{M}_{2}$ compared to monensin are very similar to those observed for bioconverted analogous products of nigericin $\left(\mathrm{N}_{1}\right.$ and $\left.\mathrm{N}_{2}\right)$ compared to it ${ }^{3)}$. For $\mathrm{M}_{3}$ a new situation is encountered compared to the nigericin biotransformation: $\mathrm{H}_{3 \mathrm{OA}}$ and $\mathrm{H}_{3 \mathrm{OB}}$ (ring C) present in monensin disappear in favor of a single proton which is shifted to the $\mathrm{CH}(\mathrm{O})$ region; similarly C-30 is shifted to the same direction. Neighboring atoms (17 and 15) are also markedly affected. As previously observed for nigericin, the bioconversion of monensin consists of two types of reaction:

i) Reduction: The opening of the terminal ring results from an enzymatic reduction of the $\delta$ hydroxy-ketone which is in equilibrium with its hemiketal tautomeric form. A chemical reduction of monensin performed with $\mathrm{NaBH}_{4}$ confirmed the presence of a reduced product. It led to two diasteroisomers $\mathrm{M}_{1}(30 \%)$ and $\mathrm{DM}_{1}(70 \%)$ that were purified by column chromatography on silica gel using a $\mathrm{MeOH}-\mathrm{CHCl}_{3}$ gradient $(4 \sim 6.5 \%$ $\mathrm{MeOH}$ in $\mathrm{CHCl}_{3}$ ). $\mathrm{M}_{1}$ was eluted first (Rf: $\mathrm{M}_{1}, 0.56$; $\mathrm{DM}_{1}, 0.47$; TLC: $\mathrm{CHCl}_{3}-\mathrm{MeOH}, 9: 1$ ). They could be identified by ${ }^{13} \mathrm{C}$ NMR and direct analogy with $\mathrm{N}_{1}$ and $\mathrm{DN}_{1}$ obtained from reduction of nigericin ${ }^{3}$. The same ${ }^{13} \mathrm{C}$ signals are shifted (C-25: $\mathrm{M}_{1} 76.58$; $\mathrm{DM}_{1}$, 73.7. C-27: $\mathrm{M}_{1}, 17.60$; $\left.\mathrm{DM}_{1}, 15.60\right)$. Consequently, the same stereochemistry of C-25 could be attributed to $\mathrm{M}_{1}$ and $\mathrm{N}_{1}$, i.e., $S$ configuration.

ii) Oxidation: $M_{2}$ is very similar to $\mathrm{N}_{2}{ }^{3)}$, the same $\mathrm{CH}_{3}$ is oxidized to $\mathrm{CH}_{2} \mathrm{OH}$, probably by a similar enzymatic process. The reaction does not continue to complete oxidation to $\mathrm{COOH}$ as observed for $\mathrm{N}_{3}$. In the case of monensin, a new site of oxidation is found involving the ethyl group. These two oxidations proceed in parallel giving $\mathrm{M}_{2}$ and $\mathrm{M}_{3}$. The stereochemistry of the $-\mathrm{CHOH}-\mathrm{CH}_{3}$ remains to be solved. As $\mathrm{M}_{3}$ is no longer an antibiotic (see later), no further investigations were performed.

The antibiotic properties of the bioconversion
Table 1. Comparison of ${ }^{13} \mathrm{C}$ chemical shifts $(\delta)$ of monensin and free acids of $\mathrm{M}_{1}, \mathrm{M}_{2}$ and $\mathrm{M}_{3}$ in $\mathrm{CDCl}_{3}$.

\begin{tabular}{ccccc}
\hline Carbon No. & Monensin & $\mathrm{M}_{1}$ & $\mathrm{M}_{2}$ & $\mathrm{M}_{3}$ \\
\hline E ring & & & & \\
$\mathbf{2 5}$ & $\mathbf{9 7 . 2 0}$ & 76.58 & 76.88 & 76.82 \\
26 & 68.00 & 64.31 & 64.48 & 64.46 \\
27 & 16.40 & 17.60 & 17.52 & 17.67 \\
24 & 35.80 & 34.85 & 34.52 & 34.94 \\
23 & 36.80 & 38.54 & 37.98 & 39.23 \\
22 & 32.90 & 34.16 & 34.68 & 34.42 \\
21 & 74.00 & 77.41 & 77.94 & 77.90 \\
D ring & & & & \\
$\mathbf{2 9}$ & 15.80 & 15.72 & $\mathbf{6 2 . 0 5}$ & 16.42 \\
$\mathbf{1 8}$ & 34.60 & 35.12 & 44.59 & 35.67 \\
19 & 31.60 & 33.22 & 29.37 & 33.63 \\
20 & 77.40 & 77.86 & 79.82 & 77.97 \\
C ring & & & & \\
$\mathbf{3 0}$ & 31.20 & 30.30 & 25.30 & $\mathbf{8 6 . 2 1}$ \\
31 & 8.60 & 8.19 & 7.49 & 18.17 \\
15 & 32.70 & 30.90 & 31.86 & 28.37 \\
$(17)^{\mathrm{a}}$ & $(85.10)$ & $(85.48)$ & $(83.48)$ & $(71.11)$ \\
\hline
\end{tabular}

a Belongs to ring $\mathrm{D}$ but influenced by variation in ethyl group 30 .

Table 2. Comparison of ${ }^{1} \mathrm{H}$ chemical shifts $(\delta)$ of monensin with $\mathrm{M}_{1}, \mathrm{M}_{2}$ and $\mathrm{M}_{3}$ as free acids in $\mathrm{CDCl}_{3}$.

\begin{tabular}{ccccc}
\hline Proton No. & Monensin & $\mathrm{M}_{1}$ & $\mathrm{M}_{2}$ & $\mathbf{M}_{3}$ \\
\hline E ring & & & & \\
$\mathbf{2 5}$ & No signal & 3.49 & 3.50 & 3.51 \\
24 & 1.49 & 1.80 & 1.99 & 1.75 \\
$23 \mathrm{~B}$ & 1.35 & 0.89 & 0.89 & 0.89 \\
23A & 1.50 & 1.85 & 1.92 & 2.01 \\
D ring & & & & \\
29 & 0.94 & 0.88 & $\mathbf{3 . 9 4} \sim \mathbf{3 . 7 9}$ & 1.01 \\
18 & 2.24 & 2.23 & 2.80 & 2.28 \\
C ring & & & & \\
30 & $1.57 \sim 1.57$ & $1.46 \sim 1.46$ & $1.72 \sim 1.55$ & $\mathbf{3 . 8 2}$ \\
31 & 0.97 & 0.90 & 0.92 & 1.20 \\
15B & 1.37 & 1.67 & 1.88 & 2.02 \\
\hline
\end{tabular}

products $\mathrm{M}_{1}, \mathrm{M}_{2}$ and $\mathrm{M}_{3}$ were evaluated classically by using the conventional dilution method with Bacillus cereus ATCC 14579 in Mueller-Hinton broth at $\mathrm{pH}$ 7. In spite of the opening of the terminal ring, $M_{1}$ is still an antibiotic with an MIC $(3.12 \mu \mathrm{g} / \mathrm{ml})$ only twice that of monensin $(1.56$ $\mu \mathrm{g} / \mathrm{ml})$. The situation is very different from that encountered for the bioconverted analogous product $\left(\mathrm{N}_{1}\right)$ whose MIC was fifty times higher that of nigericin. On the other hand, $\mathrm{M}_{2}$ and $\mathrm{M}_{3}$ are no longer antibiotics though their terminal ring is similar to $\mathbf{M}_{1}$. Indeed, $\mathrm{M}_{2}$ and $\mathrm{M}_{3}$ have additional $\mathrm{CH}_{2} \mathrm{OH}$ groups resulting from the oxidation process. As a consequence it is likely that the 
lipophilic external envelope of these molecules is too hydrophilic to be integrated in the cell membrane. The partition is in favor of the aqueous phase of the culture medium. This corresponds to a classical detoxification process of lipophilic compounds; it was already observed for nigericin ${ }^{3)}$ and grisorixin ${ }^{9 \sim 11}$ !

The complexation constants $K_{1}$ of monensin derivatives (expressed as their logarithm) for $\mathrm{Na}^{+}$ and $\mathrm{K}^{+}$were determined by the classical method of extraction in a biphasic system ${ }^{12)}$, giving the following results; monensin $\mathrm{Na}^{+}:-3.80 \pm 0.2$, $\mathrm{K}^{+}:-4.92 \pm 0.1 ; \quad \mathrm{M}_{1} \quad \mathrm{Na}^{+}:-5.22 \pm 0.2, \mathrm{~K}^{+}$: $-6.47 \pm 0.1$. Consequently $M_{1}$ still complexes with $\mathrm{Na}^{+}$and $\mathrm{K}^{+}$though less efficiently than monensin; the selectivity $\mathrm{Na}^{+}>\mathrm{K}^{+}$is maintained as well. We have shown previously ${ }^{13)}$ that $N_{1}$, in contrast, does not complex with $\mathrm{K}^{+}$and is no longer antibiotic. To explain these differences obviously linked to the structure of the bioconverted products $M_{1}$ and $N_{1}$, additional investigations are needed.

In conclusion this study of bioconversion by $S$. benihana affords interesting experimental results.

i) The detoxification process is clearly associated with the modification of the amphiphilic balance of the ionophores rather than with a change in the complexing site and shown from the difference between $\mathrm{M}_{1}$ and $\mathrm{N}_{1}$.

ii) It is possible to open the monensin terminal hemiketal ring without markedly upsetting the well organized complexing cavity of the natural metabolite.

\section{References}

1) Osborne, M.W.; J. Wenger, F. Kovzelove, R. Boyd \& M. ZANKo: Chapter 7. Effects of lasalocid and monensin on chickens. In Polyether Antibiotics. Naturally Occurring Acid Ionophores. Volume 1: Biology. Ed., J. W. WestLey, pp. 333 340, Marcel Dekker, Inc., 1982

2) LiU, C.: Chapter 3. Microbial aspects of polyether antibiotics: Activity, production, and biosynthesis. In Polyether Antibiotics. Naturally Occurring Acid Ionophores. Volume 1: Biology. Ed., J. W. WestLeY, pp. 43 102, Marcel Dekker, Inc., 1982
3) Delort, A. M; G. Jeminet, M. Sancelme \& G. DAUPHIN: Microbial conversion of nigericin in three successive steps, by Sebekia benihana. J. Antibiotics 41: $916 \sim 924,1988$

4) SEBEK, O. K. \& L. A. DOLAK: Microbial hydroxylation of novobiocin and related compounds. J. Antibiotics 37: 136 142, 1984

5) Cuer, A.; G. Dauphin, G. Jeminet, J. C. Beloeil \& J. Y. Lallemand: Complete assignment of the ${ }^{1} \mathrm{H}$ and ${ }^{13} \mathrm{C}$ spectra of the grisorixin potassium salt by means of two dimensional NMR methods. Application to the solution conformation of the molecule. Nouv. J. Chim. 9: 437 441, 1985

6) Bolte, J.; S. Caffarel-Mendes, G. Dauphin, C. DEMUYNCK \& G. JeMinet: Transport de $\mathrm{Na}^{+}$et $\mathrm{K}^{+}$, à travers une membrane liquide épaisse, par la monensine et son dérivé chloro-4 phényluréthane. Bull. Soc. Chem. 1986: 370 374, 1986

7) SETO, H. \& N. ŌTAKE: Chapter $6 .{ }^{13} \mathrm{C}$ NMR spectra of polyether antibiotics. In Polyether Antibiotics. Naturally Ocurring Acid Ionophores. Volume 2. Chemistry. Ed., J. W. Westley, pp. $335 \sim 400$, Marcel Dekker, Inc., 1982

8) ANTEUNis, M. J. O. \& N. A. RoDios: Solution conformation of monensin free acid, a typical representative of the polyetherin antibiotics. Bioorg. Chem. 7: $47 \sim 55,1978$

9) Cuer, A.; G. Dauphin \& J. C. Beloeil: Microbial conversion of grisorixin, a monovalent cation ionophorous antibiotic. J. Antibiotics 36: $20 \sim 26$, 1983

10) CUER, A. \& G. DAUphin: Microbial conversion of grisorixin: Conformational properties of a bioconversion product. Tetrahedron 41: 3725 3736, 1985

11) CUER, A. \& G. DAuphin: Structure and conformation of bioconversion products of a carboxylic ionophorous antibiotic, grisorixin, by means of twodimensional nuclear magnetic resonance. J. Chem. Soc. Perkin Trans. II 1986: 295 299, 1986

12) PFEIFFER, D. R. \& H. A. LARDY: Ionophore A23187: The effect of $\mathrm{H}^{+}$concentration complex formation with divalent and monovalent cations and the demonstration of $\mathrm{K}^{+}$transport in mitochondria mediated by A23187. Biochemistry 15: 935 943, 1976

13) David, L.; M. Chapel, J. Gandreuil, G. Jeminet \& R. DURAND: The importance of the hemi-acetal group for the ionophoric properties of nigericin. Experientia 35: $1562 \sim 1563,1979$ 